\title{
LA-UR-21-31466
}

Approved for public release; distribution is unlimited.

Title:

November 2021 Operational Highlights

Author(s):

Ali, Alee Rizwan

Intended for:

Report

Issued: 
Disclaimer:

Los Alamos National Laboratory, an affirmative action/equal opportunity employer, is operated by Triad National Security, LLC for the National Nuclear Security Administration of U.S. Department of Energy under contract 89233218CNA000001. By approving this article, the publisher recognizes that the U.S. Government retains nonexclusive, royalty-free license to publish or reproduce the published form of this contribution, or to allow others to do so, for U.S. Government purposes. Los Alamos National Laboratory requests that the publisher identify this article as work performed under the auspices of the U.S. Department of Energy. Los Alamos National Laboratory strongly supports academic freedom and a researcher's right to publish; as an institution, however, the Laboratory does not endorse the viewpoint of a publication or guarantee its technical correctness. 
Date: Nov. 16, 2021

Prepared for: Megan Bruns, Federal Program Manager

From: National Security Research Center (NSRC), Los Alamos National Laboratory (LANL)

\section{November 2021 Operational Highlights}

- Completed: 1. the initial tests of document workflows for Titan on the Red, which included standing up a software encryption capability to test data ingestion; 2. a software encryption capability in order to ingest the first data source by the end of the month; 3 . a stand-alone computer for classified ontology data entry. Titan on the Red is an artificial intelligence/machine learning system to make digitizing, cataloging, and searching NSRC collections easier and more efficient.

- Created Online Vault backups, with one copy stored at LANL and one shipped to Lawrence Livermore National Laboratory. The Online Vault is a classified, searchable library of LANL's nuclear weapons design and test history.

- Imported new Laboratory Directed Research and Development (LDRD) documents based on revised access categories.

- Bulk ingested nearly 10,000 documents via java-based PowerLoader. This application ingests metadata and content into the Online Vault to meet the requirements for the NSRC collections.

- Rehoused 300 linear feet of weapons physics documents in archival, acid-free storage folders and boxes. 